Glass \& Pole (2017)

\title{
ANSERJ
}

Vol . 8, No. 2

Autumn / Automne 2017

pp. $57-79$

Canadian Journal of Nonprofit and Social Economy Research

Revue canadienne de recherche sur les OBSL et l'économie social

\section{Collaboration Between Canadian Grantmaking Foundations: The Expression of an Increasingly Ambitious and Strategic Philanthropic Sector?}

\author{
Juniper Glass \\ Université du Québec à Montréal, Lumière Consulting \\ Nancy Pole \\ Université du Québec à Montréal, Co.spire Consulting
}

\begin{abstract}
This article critically discusses the practice of foundation collaboration in Canada and describes the context, vehicles, and forms that it takes. It is based on data from interviews with 23 key informants and a literature review of over 100 publications from grey and scholarly literature. Over the last decade, Canadian grantmaking foundations appear to be working together more often, motivated by goals of information sharing, coordination, impact, and risk mitigation. In Canada, as elsewhere, this growing practice is closely related to the trend toward strategic philanthropy, in which foundations position themselves as agents of change. The article raises cautions and criticisms about foundation collaboration, related to considerations of strategic and cultural fit as well as to existing challenges concerning philanthropy's power and legitimacy in society.
\end{abstract}

\section{RÉSUMÉ}

L'article propose de faire un examen critique des pratiques de collaboration entre fondations subventionnaires au Canada, qui représentent un domaine jusqu'ici peu exploré dans la recherche scientifique. À partir d'entretiens avec 23 informateurs clés et une recension d'écrits scientifiques et non scientifiques, l'article décrit le contexte, les chemins d'émergence et les formes que prennent ces pratiques de collaboration. Au cours de la dernière décennie, les pratiques de collaboration entre fondations subventionnaires semblent afficher une progression au Canada. Des fondations participantes indiquent être motivées par le désir de soutenir le développement des connaissances, de mieux coordonner leurs efforts, d'accroitre l'efficacité ou l'impact de leurs interventions et d'en atténuer les risques. Au Canada comme ailleurs, le développement des pratiques de collaboration entre fondations est lié à l'influence du courant de la philanthropie "stratégique » qui incite les fondations à assumer une posture plus affirmée d'agent de changement. L'article partage également des réflexions critiques au sujet de ces pratiques. Entre autres, il arrive que les organisations participantes doivent composer avec des défis de compatibilité culturelle et stratégique. De plus, ces pratiques se confrontent à des débats existants concernant le pouvoir exercé par les fondations philanthropiques et leur légitimité en tant qu'acteurs sociaux. 


\section{Glass \& Pole (2017)}

KEYWORDS / MOTS CLÉS Grantmaking foundations ; Canada ; collaboration; philanthropy / Fondations subventionnaires ; Canada ; collaboration ; philanthropie

\section{INTRODUCTION: FRAMING THE TOPIC}

Across many fields of activity, inter-organizational collaboration has come to be embraced as a primary strategy for cultivating social innovation and addressing complex problems (Marek, Brock, \& Savla, 2014; Woodland \& Hutton, 2012). In discussions pertaining to grantmaking foundations, the term "collaboration" often refers to any instance in which foundations voluntarily work together towards a common purpose (DP Evaluation, 2012; Hughes, 2005). As used in this article, the term collaboration encompasses a broad range of practices, ranging from networking for information exchange purposes to more integrated forms of collaboration requiring partners to establish joint objectives and ways of working.

While not a new practice (Buchanan, 2016), foundation collaboration has seen a growth in interest in recent years, according to several authors (James, 2013; Prager, 2011), even to the point of becoming a buzzword (Knight \& Hartnell, 2011). The increased interest appears to have followed the trend toward strategic philanthropy, characterized as a shift away from a traditional responsive relationship with grantees toward a position that assumes more active responsibility for identifying and framing problems, as well as for designing strategies to address them (Patrizi, Thompson, Coffman, \& Beer, 2013). Collaboration in this context is often seen as the only way to achieve ambitious goals, based on the recognition that multiple actors need to work together to solve complex problems. In one influential text, Katherine Fulton, Gabriel Kasper, and Barbara Kibbe (2010) note that "funders may not legally need to work with others, but if they hope to achieve significant impact on their communities-let alone on really wicked problems-they'll have to" (pp. 8-9). In many cases collaboration is perceived to be intrinsic to the solution, in the sense that different interventions from different organizations are required to address a given societal problem. Fulton et al. (2010) call upon foundations to:

combine long-standing instincts toward independent initiative and action with an emerging "network" mindset and toolkit that helps them see their work as part of a larger, diverse, and more powerful effort overall. (p. 9)

Some research indicates that the trend among foundations to adopt a more strategic posture is leading them to shift their practices with regards to collaboration. A study of 125 U.K. foundations (DP Evaluation, 2012) found a clear connection between foundations' involvement in deeper, more high-engagement forms of collaboration and their embracing a proactive agent of change role.

Most of Canada's 10,000 registered foundations operate out of the public eye (Johnston, 2012) and are likely typified by a traditional, hands-off approach to philanthropy that involves limited relationships with grantees or other foundations. In addition, the majority of Canadian foundations have small budgets and are operated by volunteer boards, characteristics that likely reduce their capacity to partner with other organizations. There are indications, however, that some philanthropic organizations are increasingly taking on an engaged and strategic role; many are indicating their desire to address root causes, with some expanding their involvement in policy and advocacy work (Elson \& Hall, 2016, 2017), and others becoming involved in international philanthropic networks (Glass, 2016). The study described in this article emerged at the request of foundations and philanthropic networks, exemplifying a growing interest in advancing the knowledge and critical understanding of foundations' role in Canadian society.

Until recently, there have been few documented practices and discussions related to collaboration among Canadian grantmaking foundations. Several reports have emerged from the thematic working groups of the Canadian Environmental Grantmakers Network (Morris, 2014, 2015; Richardson, 2012; Tomalty, 2013). Leadership at Philanthropic Foundations 


\section{Glass \& Pole (2017)}

Canada has also contributed critical reflection and observations of trends in collaboration in the sector (Pearson, 2010, 2014). Specific funder collaboratives have also published landscape assessments or case studies to contribute to improving strategy and practice in their respective fields (Langlois, 2011; Silkes, 2016). In addition, a recent series of case studies was produced by PhiLab, the Montreal Research Laboratory on Canadian Philanthropy (Berthiaume \& Lefebvre, 2016; Longtin, 2015a, 2015b; McDougall, 2016; Pole \& CFC, 2015). Despite these additions to the discourse and to the empirical knowledge base, there are very few analytical contributions in the Canadian literature that provide a broad overview of the practice of funder collaboration, the purposes it serves, and its limits.

This article describes and discusses the findings of a study conducted by the authors that aimed to address this gap and begin to provide new reference points for the Canadian philanthropic sector. This is important if foundations want to be able to capitalize upon insights and lessons learned both within the sector and beyond Canadian borders. Drawing equally upon a review of the literature both from within and outside of Canada and upon perspectives gathered from actors and observers of the Canadian foundation sector, this article describes and critically discusses foundation collaboration as a practice that is gaining prominence in Canada.

While grantmaking foundations support and engage in collaborations with a range of actors from different sectors, the focus here is on collaborations among foundations themselves, in which other types of funding partners may also participate. For the most part, these collaborations build upon the central role that foundations play as grantmakers providing funding to other third-sector organizations. Throughout this article, the terms "funder collaboration" and "foundation collaboration" are used interchangeably, reflecting the fluid boundaries of the language used in both the literature and practice.

\section{METHODOLOGY}

This article discusses a study conducted in 2016 in order to frame the topic and practice of collaboration between grantmaking foundations in Canada. It draws upon two companion working papers produced for this study, a Canadian landscape scan (Glass, 2016) and a review of the literature (Pole, 2016). As companion pieces, the literature review and landscape scan were carried out concurrently, designed to be separate and complementary contributions to the study's purpose. Taken together, they sought to describe and to understand the context, purposes, and practices of foundation collaboration in Canada and elsewhere, the potentially useful applications of this form of practice, as well as its limits and challenges.

Contemporary data and perspectives on collaboration were collected from key informants representing Canadian private, public, and community foundations and philanthropic networks. Some philanthropic sector experts active in the field, but not affiliated with a particular foundation, were also invited to participate to gather their broad perspectives. In total, 22 respondents shared their perspectives through semi-structured interviews lasting 20-45 minutes; one additional respondent provided answers to questions by email. These key informants were asked for their observations regarding the prevalence and nature of foundation collaboration in Canada, the types of collaborations they had witnessed, and the opportunities, challenges, and future trends they perceived related to the practice. Some key informants were asked follow-up questions in writing to clarify statements made during interviews. In addition, publicly available websites were consulted to collect additional information on examples of foundation collaboration identified during interviews.

Respondents were selected through snowball and convenience sampling to represent a wide range of geographic locations, scale of focus (local, regional, national) and type of philanthropic organization. A majority of key informants (18) were actively involved in collaborations between foundations at the time of the interview, either as a funder representative or as a facilitator of a collaborative (see Table 1). 
Glass \& Pole (2017)

Table 1: Description of respondents $(n=23)$

\begin{tabular}{|c|c|}
\hline \multicolumn{2}{|l|}{ Role/type of organization } \\
\hline Philanthropic network (large network of foundations) & 3 \\
\hline Private foundation & 3 \\
\hline Public foundation & 4 \\
\hline Community foundation & 1 \\
\hline Facilitator of a funder collaborative & 8 \\
\hline Independent sector experts & 4 \\
\hline \multicolumn{2}{|l|}{ Geographic scope of work } \\
\hline National & 15 \\
\hline Regional & 6 \\
\hline Local & 2 \\
\hline \multicolumn{2}{|l|}{ Province/territory of residence } \\
\hline$B C$ & 2 \\
\hline$A B$ & 1 \\
\hline MB & 1 \\
\hline NWT & 2 \\
\hline ON & 11 \\
\hline QC & 6 \\
\hline \multicolumn{2}{|l|}{ Currently involved in funder collaboration? } \\
\hline Yes & 18 \\
\hline No & 5 \\
\hline
\end{tabular}

The original literature review drew upon a total of 111 sources from the scholarly and "grey" literature from the U.S., Canada, and Europe. Sources consulted included commissioned philanthropic sector publications, case studies, reviews or evaluation reports of particular collaborative initiatives, commentaries and discussions posted in online publications and forums, as well as peer-reviewed articles, conference proceedings, and book chapters. The grey literature offered insights into the philanthropic sector's discourse on collaboration as well as into the evolving critical commentary on both discourse and practice. The majority of sources referenced in the findings and discussion section are drawn from the U.S. and U.K. literature; this is in keeping with the observation of existing gaps in the Canadian literature.

This article represents a synthesis of the two working papers, comparing themes and insights arising from interview data and from the literature, and extrapolating possible implications for the Canadian philanthropic sector. During analysis, particular attention was paid to the Canadian philanthropic context, focus, and drivers for collaboration, as well as tensions 


\section{Glass \& Pole (2017)}

and areas warranting particular attention. Except where cited, commentary on Canadian context and foundation practice is primarily derived from respondent interviews.

The article is structured to enable this dialogue between the two companion pieces making up the study. Thus, rather than present themes from the literature and findings from the landscape scan sequentially, both are presented together in the findings section, in order to better enable the side-by-side comparison of themes and insights from both.

\section{FINDINGS}

\section{The context of funder collaboration in Canada}

Over 10,000 charitable foundations are registered in Canada, divided fairly evenly between private and public foundations. Study respondents pointed out that the proportion that collaborate with each other likely remains very low, for example, as stated by a representative of a philanthropic network:

We have to remember how small the foundation community in Canada is. There is a relatively small number of foundations that are staffed and have a strategy or a set of goals that might make them think more about collaboration.

Key informants observed that Canada's geography shapes the practice of funder collaboration. One respondent from a public foundation noted that, "In Canada, national collaboration is very hard because it is such a huge, decentralized country with a low population. Most foundations don't operate at a national scale and each region has its particularities." Differences in foundations' size and scope also influence the practice, as described by a facilitator of funder collaboratives: "the foundation sector has some big players, some tiny players, some medium players, operating in different universes. When a larger foundation takes leadership, there are not a lot who are in a position to play with them." At the same time, the study did uncover examples of smaller foundations that are participating actively in and even leading collaborative initiatives.

The practice of collaboration interacts with several other shifts in Canada's foundation sector. Taken together, as one respondent who facilitates funder collaboratives stated, these shifts may point to a "maturing of the Canadian philanthropic space."

First, over the last 25 years, opportunities for foundations to meet and exchange information have expanded significantly, supported by key networks, namely Community Foundations of Canada (CFC), Philanthropic Foundations Canada (PFC), and Canadian Environmental Grantmakers Network (CEGN) (see Table 2).

\section{Table 2: Canadian foundation networks}

\begin{tabular}{|l|c|c|}
\hline & Year founded & Number of members \\
\hline Community Foundations of Canada & 1992 & 191 \\
\hline Philanthropic Foundations Canada & 1999 & 129 \\
\hline Canadian Environmental Grantmakers Network & 2001 & $\sim 65$ \\
& & (including some American organizations) \\
\hline
\end{tabular}




\section{Glass \& Pole (2017)}

Second, while the large majority of Canadian foundations are run by volunteers, anecdotal evidence indicates the paid philanthropic workforce is growing. The trend toward professionalization now includes a small community of practice specifically for individuals who manage funder collaboratives, allowing them to share learnings from this "niche professional area emerging in Canada."

Third, as mentioned earlier, respondents concurred that Canadian foundations "are becoming much more thoughtful regarding root causes and changing fundamentals as opposed to symptoms," as a representative from a public foundation observed. From this representative's perspective, the trend toward strategic philanthropy is interwoven with an interest in collaboration among foundations.

External factors also seem to be setting the scene for increased funder collaboration. Key informants noted shifts in Canada's political, social, and economic context that have encouraged foundations to seek alliances with each other, including the reduced government funding of services, the 2008-2009 economic recession, which reduced the rate of return on most endowments, and decreasing fundraising revenues by public granting organizations such as United Ways. Key informants also noted that increased public attention directed toward complex challenges, such as the Syrian refugee crisis or the impacts of colonialism documented by the Truth and Reconciliation Commission, was compelling some foundations to align with others as they explored what action to take. Foundations' stakeholders may also be contributing to a demand for greater collaboration. Some key informants indicated that grantees and communities are becoming proactive, seeking to reduce the fundraising and administrative burdens on nonprofits by requesting that funders work together more closely.

\section{Funder collaboration prevalence}

Surveys conducted in the U.S. and the U.K. have found that well over two-thirds of responding foundations report engaging in joint work with other foundations for one or more purposes (DP Evaluation, 2012; McCray, 2014). A 2017 survey of 52 Canadian private and community foundations found that nearly 75 percent collaborated with other philanthropic organizations (Philanthropic Foundations Canada, 2017), a distinct increase from the 30 percent of Philanthropic Foundations Canada members that reported engaging in such collaboration in 2010 (Pearson, 2010). Key informants in the present study also perceive that collaboration between Canadian foundations has been steadily on the rise. Approximately 40 examples of Canadian funder collaboration were mentioned by respondents, most initiated in the last five to ten years (Glass, 2016). Were a broad survey of Canadian foundations to be conducted, it is likely that additional collaborations would be identified, particularly at the regional or local level. The present study also documents an increase in the number of philanthropic affinity groups in the country, of which fourteen were established in the last decade, made up of funders who share a focus on a specific issue (see Table 3 ).

\section{Table 3: Funder affinity groups in Canada}

\begin{tabular}{|l|c|c|c|c|}
\hline Affinity group & $\begin{array}{c}\text { Year } \\
\text { initiated }\end{array}$ & Scale & $\begin{array}{c}\text { \# of funders } \\
\text { involved }\end{array}$ & $\begin{array}{c}\text { Supported by } \\
\text { network }\end{array}$ \\
\hline Circle on Philanthropy and Aboriginal Peoples & 2008 & National & $\sim 40$ & \\
\hline Arctic Funders Collaborative & 2008 & Regional/international & $\begin{array}{c}11 \\
\text { (2 Canadian } \\
+9 \text { American })\end{array}$ & \\
\hline
\end{tabular}


Glass \& Pole (2017)

\begin{tabular}{|c|c|c|c|c|}
\hline Affinity group & $\begin{array}{c}\text { Year } \\
\text { initiated }\end{array}$ & Scale & $\begin{array}{l}\text { \# of funders } \\
\text { involved }\end{array}$ & $\begin{array}{l}\text { Supported by } \\
\text { network }\end{array}$ \\
\hline Peace Grantmakers Network & 2009 & $\begin{array}{c}\text { National/most activity in } \\
\text { Québec }\end{array}$ & 9 & \\
\hline Early Child Development Funders Group & 2009 & National & 8 & PFC \\
\hline National Water Funders' Group & 2009 & National & $\sim 30$ & CEGN \\
\hline $\begin{array}{l}\text { International Alliance of Mental Health } \\
\text { Research Funders }\end{array}$ & 2009 & International & 21 & \\
\hline Great Lakes Funder Collaborative & 2011 & Regional/international & $\sim 50$ & \\
\hline Mental Health and Wellness Affinity Group & 2013 & National & $\sim 20$ & PFC \\
\hline BC Freshwater Funders Collaborative & 2014 & Regional & 18 & CEGN \\
\hline Foundation Impact Investing Affinity Group & 2014 & National & 17 & CFC \\
\hline BC Sustainable Food Systems Working Group & 2014 & Regional & $\begin{aligned} & 3 \text { funders } \\
+ & 4 \text { nonprofits }\end{aligned}$ & CEGN \\
\hline Sustainable Cities Funders Group & 2014 & National & $\sim 15$ & CEGN \\
\hline Low Carbon Future Funders Group & 2014 & National & $\sim 30$ & CEGN \\
\hline Canadian Food Funders' Group & $\sim 2014$ & National & $\sim 14$ & CFC \\
\hline
\end{tabular}

Notes: CEGN: Canadian Environmental Grantmakers Network; CFC: Community Foundations of Canada; PFC: Philanthropic Foundations Canada

\section{Vehicles of foundation collaboration}

In Canada, three main vehicles have helped to support the emergence of funder collaboratives: foundation networks, funder affinity groups, and place-based affiliations. In addition, some ad hoc funder collaboratives have emerged independently of these vehicles.

Through annual conferences and other capacity building activities for members, the national philanthropic networks mentioned earlier have played an important role in creating opportunities for foundations with overlapping interests to meet. Face to face meetings appear to be vitally important to "begin the courtship process that can ultimately lead to collaboration," as described by a respondent from a private foundation.

Affinity groups of funders focused on specific issues have also given rise to collaboration. Often affinity groups are started to support basic information sharing about who is doing what, and funding what, in a given field. Over time, however, most such working groups in Canada have expanded to include coordinated activities such as co-funding initiatives, new 


\section{Glass \& Pole (2017)}

research to build knowledge in a field, or policy advocacy. An example is the Circle on Philanthropy and Aboriginal Peoples, founded in 2008 by a group of foundations that met at a PFC conference.

Collaborations have also emerged when foundations working in a particular location or region get to know each other and become motivated to work together to achieve greater coordination and impact. Often place-based collaboratives involve not just foundations but a variety of funders, including public sector agencies, corporations, and nonprofits that flow funds to community-level initiatives. These local-level collaborations frequently have participation or leadership from community foundations or United Ways. Tides Canada has played a leading role in starting many regional pooled funds and funder affinity groups, such as the Northwest Territories On the Land Collaborative Fund and the Arctic Funders Collaborative.

Finally, foundations have also come together for single actions or time-limited initiatives in response to current events such as government cutbacks to services, the welcoming of a large wave of refugees, or a change in the government's approach to climate change. Ad hoc and emergent collaborations allow philanthropic organizations to take advantage of their ability to respond quickly and nimbly to emerging needs in a community and to new opportunities in a field.

\section{Purposes and outcomes of collaboration}

As identified in the literature, the various purposes of foundation collaborations can be grouped into four areas (Prager, 2011): learning, efficiency, impact, and influence. With a few exceptions, the purposes pursued by Canadian foundation collaborations closely reflect those described in the literature. Key informants indicated that multiple goals can coexist within one collaboration. Indeed, not all foundations involved in a collaborative effort may prioritize its purposes in the same way, as each one may have distinct reasons for participating (Prager, 2011).

At their simplest level, collaborations among grantmaking foundations provide opportunities for learning and knowledge development, either to explore new fields of interest, discover new ways of doing things, or contribute to and expand field-level knowledge (Morris, 2014; Prager, 2011; Proscio, 2010; Tomalty, 2013). As foundations enter new fields of grantmaking, knowledge sharing can help them avoid common pitfalls and reinventing the wheel (Tomalty, 2013). Several key informants cited learning as a major motivation and outcome for foundations working together. As one facilitator of a local-level collaborative described:

The collaborative was an opportunity for [the other funders] to benefit from the expertise that our foundation already had. They very much want to learn. They will now be able to read with greater understanding the funding requests that they receive and to have a more strategic approach.

In working together, foundations may also seek to make existing activities more efficient by sharing costs and due diligence responsibilities and seeking to reduce the amount of overlap or redundancy in grantmaking (Morris, 2014; Prager, 2011; TPI, 2010). Administrative efficiency for foundations appears be a less of a motivation for Canadian foundations than those described in the literature. Canadian foundations did describe a desire to make processes more efficient for grantees, however. The notion is that grantees may be better off if they have to interact with only one entity, such as a pooled fund, rather than each funder separately (DP Evaluation, 2012; James, 2013; Morris, 2014; Prager, 2011). Several Canadian key informants were aware of the administrative and communication burdens that foundation grants can place on grantees, and described ways that funder collaboratives could reduce this burden, for example by sharing site visits or developing more harmonized application and reporting requirements. One key informant described how a funder collaborative was established because community organizations were asking the foundation to "go a step further, beyond the current model of disjointed funding, in which it is up to each community organization to find and piece together many 


\section{Glass \& Pole (2017)}

different sources of funding." Another Canadian funder collaborative was created when communities requested, in the words of the facilitator of the collaborative: "Now could you get organized amongst yourselves? And not put it all on us to educate each and every funder on how to work well with us?"

A third motivation to collaborate is to increase effectiveness beyond what an individual funder could achieve on its own (Backer, 2004; Gibson, 2009; Huang \& Seldon, 2015; James, 2013; Mulgan, 2016; Pfitzer \& Stamp, 2010). While increasing impact is the most commonly cited purpose of funder collaboration, both in the literature and by key informants in this study, it is also a more complex endeavour than the first two purposes named. By working together, foundations may be seeking to expand scope, scale, and capacity, to frame more comprehensive solutions, or to identify and fill gaps in strategy or activities (DP Evaluation, 2012; GEO, 2013; Morris, 2014; Prager, 2011; Proscio, 2010; Tomalty, 2013). Key informants indicated that the increased discussion and practice of foundation collaboration in Canada is fuelled by a deepening understanding of complex societal issues, combined with a more realistic sense of the contribution that can be made by each foundation. As a respondent who works for a philanthropic network describes it: "A lot of foundations are now understanding that they would have more impact and go further, make a significant difference on a social problem if they worked together more." Respondents also believe that leveraging the diverse capacities of each foundation could lead to better outcomes. For example, the financial resources of a large foundation can allow for substantial investment by a collaborative, while the dexterity and flexibility of another foundation can allow the same collaborative to respond quickly to new needs in the field.

Fourth, foundations may work together in order to have greater combined influence with key stakeholders in the policy arena (James, 2013; Morris, 2014; Proscio, 2010) or with other foundations (Tomalty, 2013). Indeed, many authors consider that funder collaboration's greatest added value - both for participating foundations and ultimately for granteeslies in non-grant-related aspects, such as leveraging power, influence, organizational capacity, knowledge, and networks (Gibson, 2009; Marra, 2015; Prager, 2011; TPI, 2010). While the motivation to influence other stakeholders was not named as a prominent reason for foundations to work together in Canada, some key informants did name examples of Canadian foundation collaborations that aimed at influencing policy, holding governments to account, or advancing public dialogue on a societal issue.

These last two purposes_increasing impact and influence-appear to support the ambitious systems change goals espoused by some currents of strategic philanthropy. Echoing a theme found throughout the literature, a respondent who works with a philanthropic network considers that:

[a] major driver of the interest in collaboration has been an awareness that the problems that foundations are taking on are complex; by definition you can't act alone if you want to take them on, not if you want to make a difference.

Risk mitigation, although not a prominent theme in the literature, appears to be an important impetus for foundation collaboration in Canada. A quarter of respondents described aligning with other foundations as a "safe entry point" when becoming active in new geographic regions, issue areas, or philanthropic practices. Key informants indicated that foundation boards, donors, and sometimes staff are cautious about new approaches. For example a respondent reflected that when starting a multi-sector funding collaborative in a remote region, he "had to convince people to leap a bit; it helped that we could spread risk around."

Beyond intentions, what actual outcomes does funder collaboration help to achieve? The study's review of the literature did not uncover any systematic independent assessments of the outcomes achieved by foundation collaborations across 


\section{Glass \& Pole (2017)}

the entire field of practice. However, two smaller-scale reviews of funder collaboration case studies and evaluations indicate that working in collaboration has in fact allowed foundations to achieve results and synergistic effects that could not have been achieved by participating foundations acting on their own (DP Evaluation, 2102; Pole, 2016). These include achieving greater depth of understanding, reach, and engagement into a given field (Putnam-Walkerly \& Russell, 2014) and the ability to bridge gaps in services and support large initiatives beyond any single funder's capacity (Krapels, Disley, Corbett, Scraggs, \& Baruch, 2016; Lewis, Friedmann, \& Schoneboom, 2010; Parker, 2010). In one case study of a foundation collaborative that supported successful policy change initiatives, the author concluded that the collaborative itself allowed the adoption of a distinct, opportunistic granting strategy that was broadly owned and different from what participating foundations were prepared to do on their own (MacKinnon, 2006). In other similar case studies, authors concluded the collaborative lent credibility to the policy strategy, enabling foundations to approach government on a more equal footing as a group (Kaufmann, 2011) or eliminating perceptions of a behind-the-scenes agenda that a single foundation might have generated (Putnam-Walkerly \& Russell, 2014).

At the same time, collaboration among grantmakers has not been found to result in greater efficiency, at least from the funders' standpoint (DP Evaluation, 2012; Pfitzer \& Stamp, 2010). Several key informants concurred with the literature contending that, in the short- to medium-term, working in concert with other philanthropic organizations often takes more time and human resources than acting alone (Gibson, 2009; Morris, 2014; Prager, 2011).

\section{Types of collaboration}

Collaborations among grantmaking foundations take a range of different forms. Drawing upon the literature, the study proposed a continuum of collaboration "types" (see Table 4). These range from "lighter-touch" collaborations, in which participants generally retain their full autonomy over strategy and granting processes, to "higher-stakes" collaborations, involving a major commitment of time and money, the loss of unilateral decision-making control, and the assumption of shared reputational risks. The types at the "higher-stakes" end of the continuum tend to emerge in response to more complex challenges, where the answers to problems are not known in advance, and no single entity has the resources or the authority to bring about change. As with all typologies, this one does not perfectly capture reality, and most actual foundation collaborations combine different purposes and take on hybrid forms that evolve over their life course. Still, it provides a useful framing device to describe a number of actual foundation collaborations in Canada, and to understand the logic, constraints, and possibilities that underpin them.

\section{Table 4: Forms of foundation collaboration by degree of integration}

Form, purposes, characteristics

Information or knowledge exchange: purpose is to provide ongoing venues for funders to exchange information, discuss common interests, and learn about issues of common relevance. Membership tends to be large, inclusive, and fluid (network model).

Co-learning and knowledge production: purpose is to facilitate funders' ongoing engagement and exploration around a defined issue or problem, usually with the goal of developing a common intellectual framework, a shared approach or agenda, and/or positioning an issue differently in the foundation world. Also assists in identifying emerging issues and strategic opportunities. Can involve jointly commissioned research.
References

DP Evaluation (2012), Hamilton

(2002), Huang \& Seldon (2015),

Marra (2015), Pfitzer \& Stamp

(2010), Prager (2011)

Gibson (2009), Hamilton (2002) 


\section{Glass \& Pole (2017)}

\begin{tabular}{|c|c|}
\hline Form, purposes, characteristics & References \\
\hline $\begin{array}{l}\text { Informal alignment, coordination, strategic co-funding: purpose is to align different } \\
\text { foundations' resources within a common area of activity. Rationale might be to avoid } \\
\text { duplication, increase coverage, or ensure complementary support. Each partner retains } \\
\text { ownership of its individual strategies and autonomy over its own grantmaking. Activity } \\
\text { focus tends to be information sharing with a view to facilitate aligned action. }\end{array}$ & \multirow{2}{*}{$\begin{array}{l}\text { DP Evaluation (2012), Gair (2012), } \\
\text { Gibson (2009), Hamilton (2002), } \\
\text { Huang \& Seldon (2015), Marra } \\
\text { (2015), Morris (2014) }\end{array}$} \\
\hline $\begin{array}{l}\text { Formal alignment, coordination, strategic co-funding: similar purpose and rationale as for } \\
\text { informal alignment. Some joint decision-making and some established rules for } \\
\text { governance and contribution. }\end{array}$ & \\
\hline $\begin{array}{l}\text { Coinvestment in an existing entity/initiative: a model where one funder raises money } \\
\text { from other donors to support a specific initiative or organization. A variant of this is "fund } \\
\text { the funder," where a group of funders invest in another funder with strong expertise in a } \\
\text { content area. Re-granting funder has full decision-making authority. }\end{array}$ & Huang \& Seldon (2015) \\
\hline $\begin{array}{l}\text { Pooled funding: purpose is to create a funding pool from multiple sources in order to re- } \\
\text { grant for a given area/sector/set of issues. Decision-making, administrative, and } \\
\text { governance structures vary widely. }\end{array}$ & $\begin{array}{l}\text { DP Evaluation (2012), Gair (2012), } \\
\text { Gibson (2009), Hamilton (2002), } \\
\text { Proscio (2010) }\end{array}$ \\
\hline $\begin{array}{l}\text { Joint ventures: creation of a new entity, either for the purpose of re-granting or of } \\
\text { operating particular projects. Usually emerge out of perceived void in policy and/or } \\
\text { practice, to raise the profile of an issue, or to develop new ideas. }\end{array}$ & $\begin{array}{l}\text { DP Evaluation (2012), Hamilton } \\
\text { (2002), Huang \& Seldon (2015) }\end{array}$ \\
\hline $\begin{array}{l}\text { Joint advocacy: purpose is to plan, coordinate, and conduct direct policy advocacy as } \\
\text { foundations (as opposed to through funded grantees), in order to influence public } \\
\text { attitudes and debate about a policy issue of concern. }\end{array}$ & $\begin{array}{l}\text { DP Evaluation (2012), Prager } \\
\text { (2011) }\end{array}$ \\
\hline
\end{tabular}

These types can be clustered into three groups, roughly corresponding to the various purposes of foundation collaboration discussed earlier.

\section{Alignment around information and knowledge}

In the most basic and informal expression of collaboration, foundations come together to share information about granting strategies, experiences in a particular field, and other knowledge that impacts foundations' work. An example of this is the Affinity Group for Foundation Impact Investors, an informal pan-Canadian network of 17 public and private foundations that actively dedicate part of their endowments to mission-related investments. Members share information about their investment criteria, challenges faced in creating an impact investing program in their foundation and how they have addressed them, as well as their current mission-related investments. There is no pressure to embark in collaborative activities with each other.

Foundations that come together for more active co-learning and knowledge production purposes may collectively finance research related to their field of focus, map the landscape of organizations and issues with a view to identifying strategic opportunities for philanthropy, or support activities that identify and share best practices in their field of focus. Canadian examples include the Peace Grantmakers Network (nine foundations), which has organized several events to highlight 


\section{Glass \& Pole (2017)}

knowledge and practices to prevent bullying, and the Low Carbon Futures Funders Group (seven foundations), which supported the production of En Route to a Low-Carbon Future: A Landscape Assessment for Canadian Grantmakers (Dunsky Energy Consulting, 2015).

\section{Collaboration for more efficient or effective grantmaking}

Informal alignment, coordination, and strategic co-funding arrangements tend to involve a small number of foundations, and develop from an existing relationship to respond to an opportunity or to seek complementarity in a particular field. The lack of formal collaborative structure can allow for each foundation to act nimbly, using its existing grantmaking and governance procedures to take advantage of emerging opportunities. For example, Canada's social innovation infrastructure has grown significantly over the last decade, largely due to distinct but complementary initiatives such as Social Innovation Generation supported by the McConnell Foundation and Ontario's School for Social Entrepreneurs supported by the Ontario Trillium Foundation. These foundations communicated regularly in order to coordinate their work in the field.

In more formal alignment, coordination, and co-funding arrangements, foundations come together to discuss and set joint priorities, while maintaining their individual granting processes. In some arrangements, the staff of a foundation will administer the group, while in others foundations will jointly fund a coordinator position. As an example of the latter, the BC Freshwater Funders' Collaborative brings together 18 funding organizations (private and public foundations, government and quasi-governmental agencies, and corporate funders); with the support of paid coordination staff, it focuses on four core areas of alignment, including grantmaking aimed at ensuring effective implementation of the British Columbia Water Sustainability Act (Morris, T. personal communication, 2017).

Co-investment describes a form of collaboration where one foundation, often with particular expertise or capacity, takes the lead to coordinate an initiative while engaging other funders. Led by Centraide/United Way Montréal, Montréal's Collective Impact Project is an example of this, involving eight other private and public foundations in supporting collective-impact style neighbourhood-level poverty reduction efforts.

With pooled funds, participating foundations must reach an agreement about granting strategy, priorities, and processes. Not only must partner foundations invest time and energy in the collaborative's governance, they must also adapt their own granting procedures to align with what has been jointly agreed. As an example, the Northern Manitoba Food, Culture and Community Fund involves fifteen public, private, and community foundations and government and corporate donors in a re-granting initiative that seeks to increase food security and economic development in Northern Manitoba communities, including several indigenous communities (McDougall, 2016).

\section{Collaboration beyond grantmaking}

Joint ventures involve the creation of a new entity either for the purpose of re-granting or operating particular projects, in response to a perceived void in policy or practice, to raise the profile of an issue. For example, several foundations collaborated to fund the establishment of Canada's Ecofiscal Commission (CEC) to explore and promote innovative fiscal policies that help increase the country's economic and environmental prosperity. Participating funders committed to multiyear funding and developed a working agreement about additional non-financial support provided to the CEC to help ensure its success.

Some foundations plan, coordinate, and jointly undertake policy advocacy on their own (as opposed to through funded grantees), in order to influence attitudes and debate about a policy issue of concern (DP Evaluation, 2012; Jung, Kaufmann, \& Harrow, 2014; Prager, 2011; Putnam-Walkerly \& Russell, 2014). As Peter Elson and Sara Hall (2016) note, 


\section{Glass \& Pole (2017)}

foundation sector leaders are urging grantmaking foundations to embrace advocacy and public policy engagement as a way to leverage their influence and improve their impact. Recent research (Elson \& Hall, 2016) confirms that leading grantmaking foundations in Canada engage in the policy influence process in both direct and indirect ways, by leveraging their own experience, knowledge, and reputation to frame issues or weigh in on policy debates, and by supporting grant recipients that actively engage in the public policy process. However, cases of foundations joining up to engage collaboratively in direct policy influence action appear to be rare. The Early Child Development Funders Group, which brings together eight private foundations to promote quality, publicly funded early childhood education (ECE), published an open letter in 2015, calling on governments to recognize the importance of ECE to building a healthy, prosperous country (Elson \& Hall, 2016; Longtin, 2015a). The group met with public sector decision-makers in various provinces to promote an evidence-based approach to ECE.

\section{DISCUSSION}

While philanthropic discourse often reflects a pervasive normative assumption that collaboration is always a good thing (Knight \& Hartnell, 2011), the study's key informants joined critical commentators from the literature in offering a more nuanced assessment. The challenges and criticisms of funder collaboration are both internal, concerning grantmaking foundations' own practices, and external, concerning foundations' ambiguous and contested place in society. These internal and external challenges and criticisms are discussed in turn below, interspersing their framing in the literature with the observations shared by the study's key informants.

\section{Challenges of strategic fit, culture, and capacity to collaborate}

Despite increased attention in recent years to foundation collaboration and its reported prevalence in practice, many commentators within the U.S. and U.K. literature express reservations as to the true prevalence of the "higher-stakes" collaborative practices among foundations, considering that the practice lags well behind the rhetoric (Hughes, 2005; James, 2013; Kabel, 2016; Kramer, 2014; Pfitzer \& Stamp, 2010; Seldon, Tierney, \& Fernando, 2013). Several key informants observed that many collaborative efforts among Canadian foundations do not go beyond basic knowledge sharing. One respondent from a public foundation observed that:

funders are very effective at keeping each other informed around what they're doing, talking about common goals, looking for opportunities ... [but] we've made very little progress on funder collaboration if what we mean is funders actually sitting together and jointly funding initiatives in a coordinated fashion ... in a truly collaborative way in terms of how the funds are allocated and managed.

"Higher-stakes" forms of collaboration that require significant engagement and alignment between grantmaking foundations are frequently described as a counter-normative practice, that is, one that contrasts with foundations' usual way of operating. Certain authors (Bartczak \& Spearce, 2012) suggest in fact that foundations' default position is to go it alone. Others contend that collaboration runs contrary to foundations' natural impulses, challenging their attachment to autonomy and to their traditional ways of working (Gibson, 2009; Leat, 2009). Some authors go so far as to suggest that few foundations will agree to work with each other purely for the sake of social impact, if there are no individual or organizational benefits to be gained (Knight \& Hartnell, 2011; Kramer, 2014). This may be particularly true for public foundations that need to compete for fundraising dollars (Bernholz, Fulton, \& Kasper, 2005; Graddy \& Morgan, 2006; Paarlberg \& Meinhold, 2012). Several study respondents noted that this challenge does arise in the Canadian philanthropic field. For example, public foundations that must fundraise to support granting in their region are motivated to maintain their unique niche and public positioning in order to attract donors. This in turn can lessen the incentive for them to work with other similar foundations on joint initiatives for which credit must be shared. 


\section{Glass \& Pole (2017)}

The more demanding forms of collaboration, such as pooled funding, require of their partners that they compromise and relinquish some control over decision-making (Gibson, 2009; Morris, 2014; Prager, 2011), and may even entail a loss of participating foundations' authority, brand identity, and their ability to leave their stamp on ideas and grant transactions (Proscio, 2010). One study respondent's experience speaks to this challenge:

I have been involved in collaborative efforts where one of the partners claimed success as if no one else was involved. It's a question of attribution: in a collaborative, it's more difficult to demonstrate individual foundations' impact.

However, not all key informants agreed with this assessment; some consider that leaders within the Canadian philanthropic sector are moving past these traditional barriers and demonstrating a commitment to innovation and impact instead of individual career or organizational interests. As one stated: "We are becoming more issues focused as a sector, willing to leave our logos and egos at the door."

When collaboration takes a form that involves a high degree of alignment between participating foundations, it challenges each organization to adapt its internal systems, practices, and procedures (Backer, 2004; Bartczak, 2015; Mulgan, 2016; Prager, 2011). Invariably these requirements run up against the different cultures, institutional norms, accountability structures, and constituencies of participating organizations (Gibson, 2009; Kabel, 2016; Morris, 2014). As authors such as Amy Celep, Sara Brenner, and Rachel Mosher-Williams (2016) and Douglas Easterling and Allison Metz (2016) have pointed out, such adaptation often requires conscious attention to shifting organizational culture, a notoriously challenging endeavour in any sort of organization. Several study respondents had experienced the challenges of trying to collaborate while each funder felt first and foremost to "mind their own shop," as one manager of a funder collaborative said. Another key informant believed that the internal differences among foundations attempting to work together was one of the major difficulties in the implementation of a collaborative:

Funders are very different from each other and this shouldn't be underestimated. They are different in purposes, cultures, size, degree of staffing, dominant personalities on the board, whether or not their original donors are living, the level of control or flexibility. Not getting those on the table early can be a big stumbling block.

The need to achieve consensus among partners as well as buy-in from within each organization's senior leadership can significantly slow the pace of work, with consequences for relations with external partners (James, 2013; Morris, 2014; Wiley, Bierly, Reeve, \& Smith, 2013). Respondents who were experienced with the practice recognized that collaboration is an investment in itself. One facilitator of a funder collaborative cautioned other foundations: "Don't be naive about how much time it's going to take to do it well. Investing in developing trust and confidence takes time."

The push for consensus can also squeeze out the best thinking, which is based upon vigorous, robust debate, and drive toward simpler, less controversial, and ultimately less suitable resolutions (Mulgan, 2016). As one respondent who is active on boards of several Canadian foundations observed:

There's a real trade-off to collaboration - there have to be compromises and that can lead to a loss of independence of theory, thinking, approach. There can be a drive to the lowest common denominator in which riskier approaches get sacrificed. Collaboration can squeeze out innovation. That's one of the costs that rarely gets recognized. 


\section{Glass \& Pole (2017)}

Indeed, there are many situations in which collaboration is not the most appropriate strategy. When dealing with controversial issues, it may be easier for one funder acting alone to take the necessary risks (DP Evaluation, 2012). Because it often entails a slower pace of work, collaboration may not always be a productive option when radical innovation is required (Mulgan, 2016), or when a fast and flexible funding decision is necessary to take advantage of a window of opportunity. Several key informants concurred, summarizing the strategic advantages and tradeoffs of collaboration with the familiar saying: "If you want to go fast, go alone; if you want to go far, go with others." Thus, foundations must assess each opportunity to collaborate against their own strategic goals (Backer, 2004; Huang \& Seldon, 2015; Knight \& Hartnell, 2011) and based on their organization's readiness to collaborate (DP Evaluation, 2012; Pfitzer \& Stamp, 2010; Prager, 2011).

\section{Challenges of power and legitimacy}

Some of the literature engages more critically with the discourse and practice of foundation collaboration, locating it within broader debates about foundations' legitimate role. In particular, Geoff Mulgan (2016) contends that collaborations between foundations act to concentrate and amplify the challenges of democracy that private philanthropy already poses.

Foundations are hybrid actors that sometimes span the boundaries between state, market, and civil society (Fontan, 2015), and there is no broad societal consensus on their role. Within the philanthropic field, a frequently articulated view is that foundations' freedom from the constraints of political and market accountability affords them the autonomy, ability to take risks, and longer time horizon needed to develop new ways to address complex problems (Anheier \& Leat, 2006; Edwards, 2011; Reich, 2013). Foundations can leverage this freedom to act in order to foster social innovation, support the scaling up of promising practices, and extend their influence toward policy change in support of their goals.

This unique position gives foundations a potential influence that extends beyond their proportional weight in the funding universe. While the amount of funds granted by Canadian foundations is small compared to total charitable donations by individuals, sector commentators consider that foundations' institutional status gives them a greater strategic capacity and staying power than most individual donors (Imagine Canada \& Philanthropic Foundations Canada, 2014).

In this context, one democratic challenge has to do with philanthropy's legitimate role in shaping or driving collaborative efforts to address complex social problems. According to a common criticism, the license enjoyed by foundations to set and pursue their own priorities and strategies comes from a mix of private and public funds (foregone tax), and yet there is nothing to hold them accountable to the public interest with regards to these priorities and strategies (Anheier \& Leat, 2013; Edwards, 2011). Mulgan (2016) argues that by joining forces, foundations may develop a weight that allows them to circumvent the authority invested in the appropriate level of government, claiming a competing legitimacy to that of elected officials without the corresponding mechanisms of public accountability.

Concerns about the role of foundations in public policy are not new, but they appear to be on the upswing, at least in the U.S. (Buchanan, 2016). In Canada, these debates appear to be less developed, ${ }^{1}$ although this may change as the role of Canadian foundations in the policy process becomes more visible.

Foundation collaboration can also pose a second problem of democracy. When funders work together to increase their own efficiency and effectiveness, they can amplify existing inequitable power dynamics between funder and grantee (DP Evaluation, 2012; Mulgan, 2016). Coordination among funders increases their capacity to direct grantee strategy, reducing the autonomy of communities to determine how they wish to respond to the challenges they face.

Some key informants conveyed an awareness that grantees likely perceive funder collaboration very differently than foundations, countering the commonly expressed view that funder collaboration can simplify life for grantees. Respondents 


\section{Glass \& Pole (2017)}

contended that grantees may in fact find funder collaboratives to be more confusing and opaque to work with than individual foundations, such as when the different roles of collaborative members are unclear or when the goals or granting processes of the collaborative itself are not transparent.

The distortion induced by the funder-fundee power dynamic can become even more acute when foundations act as both funder and member of an implementing coalition (DP Evaluation, 2012), an issue that has been raised within several critical reflections on the funder's role in collective impact. In much of the earlier collective impact literature and many of its profiled initiatives, funders act as catalysts and conveners and remain active participants in the governance bodies of the initiatives (Hanleybrown, Kania, \& Kramer, 2012; Kania \& Kramer, 2011, 2013; Turner, Merchant, Kania, \& Martin, 2012). In the view espoused by the framework's early promoters, foundations are uniquely positioned to provide leadership to cross-sector collective action, because they have knowledge and influence over the nonprofit actors working in the target issue area. Others contend that it is unrealistic to think funders will be just one voice among many within a collective impact effort, given their financial and convening power (Carson, 2012). A review of funder-driven community change initiatives found in fact that such initiatives can "distort local energy, provoke resistance, and disrupt existing relationships among local players and programs" (Kubisch, Auspos, Brown, \& Dewar, 2011, p. 140). Several key informants in this study cautioned that funder-led projects were often too disconnected from communities' priorities and approaches to be successful. One facilitator of funder collaboratives described a failed initiative started by a national network of foundations that was "too top-down" and did not generate "the level of buy in required" from local funders and communities. Another key informant summed up how foundations must share power if they are to be involved in meaningful cross-sector, multistakeholder initiatives:

There's a kind of elitist approach that is part of how foundations operate generally. We have to get away from, "We foundations are going to get together to solve your problems more effectively" to: "We can't solve your problems without you, and therefore we have to figure out how we work with you to develop a common perception of what the problem is that we're trying to address."

\section{Aligning expectations in cross-sector collaborations}

A number of commentators and key informants speak to the importance of going beyond collaboration only between foundations to engage partners across sectors (Parker, 2010; Prager, 2011; Proscio, 2010). This is consistent with the view that in taking up a strategic change focus, foundations need to locate themselves as one player within a broader ecosystem of actors that extends beyond their grantees and involves organizations in other spheres of activity (Kania, Kramer, \& Russell, 2014; Wei-Skillern, Silver, \& Heitz, 2013). Indeed, the ambition of some grantmaking foundations to engage in systems change may lead them to recognize that a range of actors from all spheres (government, the private sector, and civil society) have a role to play in designing, implementing, and scaling up the social innovations that may be able to resolve "messy," intractable problems.

In keeping with what appears to be an emerging recognition among Canadian foundations that cross-sector collaborations have greater capacity to engage systems change, key informants foresaw a growing trend toward these types of collaborations in Canada. Some Canadian commentators even consider that collaboration's greatest "value add" lies in these relationships between foundations and governments, universities, and the private sector (Chouinard \& Bird, cited in Philanthropic Foundations Canada, 2012).

Foundations' engagement in cross-sector networks ushers in new complexities, as other sectors' view of philanthropy's role and contribution may not align with a foundation's own intentions and expectations (Healy \& Donnelly-Cox, 2016). On the one hand, governments may welcome an increasing role for private philanthropy as a way to compensate for the 


\section{Glass \& Pole (2017)}

declining capacity and legitimacy of the public sector to act alone when setting and delivering policy and programs (Jung \& Harrow, 2015). On the other hand, foundations must not overestimate the willingness of other actors-whether they be grantee communities or public sector partners - to serve as agents of foundation-determined strategy (Easterling \& Metz, 2016). As grantmaking foundations achieve more visibility in Canada, there needs to be open dialogue and debate about the role that they are best positioned to play within these boundary-spanning sectors of activity. Foundations entering into collaboration with each other and with organizations from other spheres of activity will do well to be aware of the range of expectations that others have of their role, and seek to clarify and align these expectations where possible.

\section{IMPLICATIONS FOR CANADIAN PHILANTHROPY}

Canadian foundations are actively exploring inter-funder collaboration. The next decade will likely see considerable evolution in a practice that is still currently in its early stages. Several respondents described their collaborations as ways to test new approaches and learn as they go. Since collaboration is necessarily a dynamic and evolving practice (Woodland \& Hutton, 2012), the learning and reflection orientation that many respondents expressed is likely well suited to the ongoing adjustments in strategy and action that the practice demands. While there are not yet many publicly shared Canadian examples to draw upon, many respondents expressed a desire to learn from others' experiences, seeking out examples and lessons from the U.S. and taking part in meaningful learning and exchange with other Canadian funder collaboratives.

Some respondents conveyed a broadly shared perception that the development of the Canadian philanthropic sector has lagged behind that of the U.S., with most Canadian foundations working in isolation and out of the public eye, and with relatively few choosing to publicly communicate their strategic objectives. However, along with other recent research, ${ }^{2}$ this study lends weight to the sense that a growing part of the Canadian foundation sector is embracing ambitious goals and designing strategies to support them. This study indicates that for Canadian foundations seeking to have a greater impact through their philanthropy, many see collaboration as a way to best leverage their role and make the best use of their resources. As many foundations take a more active and public position in their fields of interest, they appear to be adopting more sophisticated strategies and approaches, which often include collaboration with other actors.

This raises a new challenge. While most discussions reflect the assumption that working in collaboration leads to stronger and more effective philanthropic strategy, as with the other challenges discussed above, collaboration may in fact serve to amplify certain commonly occurring pitfalls that many individual foundations encounter as they design, implement, and evaluate their strategies. Past discussions have highlighted the difficulties that foundations encounter in clearly articulating the role that they themselves will play within change strategies that most often focus on the action of grantees (Patton, Foote, \& Radner, 2015; Patrizi \& Thompson, 2011); in developing strategy that is based on realistic expectations of what will happen in response to the foundation's inputs (Buteau, Buchanan, \& Brock, 2009; Easterling \& Metz, 2016); and in learning from implementation and adapting strategy in response to this (Coffman, Beer, Patrizi, \& Thompson, 2013; Easterling \& Metz, 2016; Patrizi et al., 2013; Patrizi \& Thompson, 201; Patton \& Patrizi, 2010). The pressures of working together to develop joint strategy may act to compound the challenges that foundations already contend with on an individual basis.

Along with the expansion of foundation collaboration and networks in Canada over the last decade, the reflective orientation communicated by respondents would seem to indicate that there is potential for the development of more democratic, innovative, and collaborative philanthropic practices as the sector evolves. In order to fulfill this potential, the sector should consider engaging with the following questions: How can foundations continue to develop their collaborative activity with each other while also building equitable relationships with grantees and communities? How can foundations more fully step into the role they can play in influencing change, while also recognizing their limits and the contribution they are best positioned to make within cross-sector collaborations? 


\section{Glass \& Pole (2017)}

\section{CONCLUSION: LIMITATIONS AND OPPORTUNITIES FOR FUTURE RESEARCH AND DIALOGUE}

The study discussed here lays the foundations for understanding and critically examining the practice of foundation collaboration in the Canadian context. In addition, this article provides a reference point for future research and for continuing dialogue about the potential, limits, and challenges of philanthropic foundations' engagement with contemporary social and ecological problems.

As the study was based on interviews with actors and close observers within the Canadian philanthropic sector, its findings do not provide an exhaustive portrait of the current state of foundation collaborations in Canada. Regular surveys of Canadian foundations could help to fill data gaps about the prevalence and types of collaborations, as well as other aspects of philanthropic practice.

Future research could further engage with some of the themes and tensions raised in this study, grounding them in the evolving experiences, reflections, and debates taking place in the Canadian context. Two directions appear to be particularly important for developing this knowledge base. First, evaluative case studies on Canadian foundations' collaborative efforts could seek to document their outcomes and assess whether and under what conditions they are able to achieve the synergistic effects reported by reviews of foundation collaboratives in other countries (DP Evaluation, 2012; Pole, 2016).

Second, future studies on the subject of inter-foundation or funder collaboration should incorporate the perspective of non-foundation stakeholders; these should include intended beneficiaries, but also other actors who fall within the spheres of influence of foundation philanthropy. The study discussed here draws upon the viewpoints of key informants who have actively worked within the philanthropic sector, and they likely reflect a certain positive bias regarding grantmaking foundations' role and social contribution. As mentioned above, other stakeholders' viewpoints on the contributions and effects of foundations acting together may well be different from the viewpoint held by foundations themselves.

\section{NOTES}

1. There are a few notable exceptions to this rule: Sylvain Lefèvre (2015) discusses a Canadian angle to the challenges that philanthropic money may pose to democracy; the model of public-philanthropic partnership piloted in Québec by the Fondation Lucie et André Chagnon was contested, having been seen to impose social priorities and commit public funds to these priorities without having emerged from a process of public debate.

2. A 2014-2017 Social Sciences and Humanities Research Council Partnership Development Project sought to better understand the roles that Canadian foundations are playing to address complex social problems and support social change. A number of the working papers and articles produced contribute to describing this strategic evolution within the Canadian foundation sector (PhiLab, n.d.).

\section{WEBSITES}

Arctic Funders Collaborative, http://arcticfunders.com/

Canada's Ecofiscal Commission, https://ecofiscal.ca/

Canadian Environmental Grantmakers Network, http://www.cegn.org/

The Circle on Philanthropy and Aboriginal Peoples, http://www.philanthropyandaboriginalpeoples.ca/

Centraide of Greater Montreal Collective Impact Project, http://www.centraide-mtl.org/en/agencies/collective-impact-project/ Community Foundations of Canada, http://communityfoundations.ca/

Early Child Development Funders Group, http://ecdfwg.ca/en/ 


\section{Glass \& Pole (2017)}

Fondation Lucie et André Chagnon, https://fondationchagnon.org/fr/index.aspx

International Alliance of Mental Health Research Funders, http://iamhrf.org/

Northern Manitoba Food, Culture and Community Fund, http://www.nmfccc.ca/

Northwest Territories On the Land Collaborative Fund, http://www.nwtontheland.ca/

Peace Grantmakers Network, http://peacegrantmakers.ca/wp/

Philanthropic Foundations Canada, http://pfc.ca/

Tides Canada, http://tidescanada.org/

United Way Centraide Canada, http://www.unitedway.ca/

\section{REFERENCES}

Anheier, H.K., \& Leat, D. (2006). Creative philanthropy: Toward a new philanthropy for the 21 st century. London, UK: Routledge.

Anheier, H.K., \& Leat, D. (2013). Philanthropic foundations: What rationales? Social Research, 80(2), 449-472.

Backer, T.E. (2004). Collaboration approaches for smaller foundations. Baltimore, MD: Annie E. Casey Foundation.

Bartczak, L. (2015). Building collaboration from the inside out. Washington, DC: Grantmakers for Effective Organizations.

Bartczak, L., \& Scearce, L. (2012). Can philanthropy be networked and strategic? Alliance Magazine, 17(4). URL: http://www.alliancemagazine.org/feature/can-philanthropy-be-networked-and-strategic/ [May 12, 2016].

Bernholz, L., Fulton, K., \& Kasper, G. (2005). On the brink of new promise: The future of U.S. community foundations. San Francisco, CA: Blueprint Research \& Design and The Monitor Group.

Berthiaume, A., \& Lefèvre, S. (2016). Le collectif québécois des fondations sur les inégalités sociales. Une étude de cas exploratoire sur la collaboration de fondations québécoises. Working paper \#11. Montréal, QC: PhiLab.

Buchanan, P. (2016). Big issues, many questions: An essay on the pressing issues facing U.S. foundation leaders and boards. Cambridge, MA: Center for Effective Philanthropy.

Buteau, E., Buchanan, P., \& Brock, A. (2009). Essentials of foundation strategy. Cambridge, MA: Center for Effective Philanthropy.

Carson, E. (2012). Rethinking collective impact: Part two. Huffington Post. URL: http://www.huffingtonpost.com lemmett-d-carson/collective-impact-_b_1847972.html [January 23, 2015].

Celep, A., Brenner, S., \& Mosher-Williams, R. (2016). Internal culture, external impact: How a change-making culture positions foundations to achieve transformational change. The Foundation Review, 8(1), 116-129.

Coffman, J., Beer, T., Patrizi, P., \& Thompson, E.H. (2013). Benchmarking evaluation in foundations: Do we know what we're doing? The Foundation Review, 5(2), 36-51.

DP Evaluation (2012). A funder conundrum: Choices that funders face in bringing about positive social change. London, UK: Association of Charitable Foundations.

Dunsky Energy Consulting (2015). En route to a low-carbon future: A landscape assessment for Canadian grantmakers. Toronto, ON: Canadian Environmental Grantmakers Network. URL: http://www.cegn.org/wp-content /uploads/2015/11/EnRouteToALowCarbonFuture.pdf [May 20, 2016].

Easterling, D., \& Metz, A. (2016). Getting real with strategy: Insights from implementation science. The Foundation Review, 8(2), 97-115.

Edwards, M. (2011). The role and limitations of philanthropy. Commissioned paper for the Bellagio Initiative. East Sussex, UK: Institute of Development Studies, The Resource Alliance \& Rockefeller Foundation.

Elson, P., \& Hall, S. (2016). System change agents: A profile of policy-focused grantmaking foundation engagement in public policy. ANSERJ, Canadian Journal of Nonprofit and Social Economy Research, 7(2), 57-78. 


\section{Glass \& Pole (2017)}

Fontan, J.-M. (2015). Place et rôle des fondations subventionnaires dans l'écosystème philanthropique. In Institut Mallet (Ed.), Écosystème philanthropique : perspectives, perceptions et échanges (pp. 113-130). Proceedings of the Sommet 2015 sur la culture philanthropique. Montréal, QC: Institut Mallet.

Fulton, K., Kasper, G., \& Kibbe, B. (2010). What's next for philanthropy: Acting bigger and adapting better in a networked world. San Francisco, CA: Monitor Institute.

Gair, C. (2013). Strategic co-funding: An approach for expanded impact. San Francisco, CA \& Washington, DC: REDF \& Grantmakers for Effective Organizations.

Gibson, C. (2009). Funder collaboratives: Why and how funders work together. New York, NY: GrantCraft (The Foundation Center).

Glass, J. (2016). The Landscape of Foundations Collaborating in Canada. Working Paper \#13. Montréal, QC: PhiLab.

Graddy, E.A., \& Morgan, D.L. (2006). Community foundations, organizational strategy, and public policy. Nonprofit and Voluntary Sector Quarterly, 35(4), 605-630.

Grantmakers for Effective Organizations (2013). The promise and pitfalls of local and national funder collaborations: Lessons learned from the Social Innovation Fund. Scaling What Works Lessons Learned series. Washington, DC: Grantmakers for Effective Organizations.

Hamilton, R. (2002). Moving ideas and money: Issues and opportunities in funder funding collaboratives. Chicago, IL: University of Chicago, Chapin Hall Center for Children.

Hanleybrown, F., Kania, J., \& Kramer, M. (2012). Channeling change: Making collective impact work. Stanford Social Innovation Review, 9, 1-8.

Healy, J., \& Donnelly-Cox, G. (2016). The evolving state relationship: Implications of "Big Societies" and shrinking states. In T. Jung, S.D. Phillips, \& J. Harrow (Eds.), The Routledge Companion to Philanthropy (pp. 200-212). Oxon, UK: Routledge.

Huang, J., \& Seldon, W. (2015). Lessons in funder collaboration: What the Packard Foundation has learned about working with other funders. Boston, MA: Bridgespan Group.

Hughes, R. (2005). Philanthropies working together: Myths and realities. New York, NY: The Foundation Center. Imagine Canada and Philanthropic Foundations Canada. (2014). Assets and giving trends of Canada's grantmaking foundations. Ottawa, ON \& Montréal, QC: Imagine Canada and Philanthropic Foundations Canada.

James, R. (2013). Funder collaboration: A compelling and cautionary tale. Praxis note no 64. Oxford, UK: INTRAC (International NGO Training and Praxis Centre).

Johnston, P. (2012). Good grantmaking: A guide for Canadian foundations. Montréal, QC: Philanthropic Foundations Canada. Jung, T., \& Harrow, J. (2015). New development: Philanthropy in networked governance-- treading with care. Public Money and Management, 35(1), 47-52.

Jung, T., Kaufmann, J., \& Harrow, J. (2014). When funders do direct advocacy: An exploration of the United Kingdom's Corston Independent Funders' Coalition. Nonprofit and Voluntary Sector Quarterly, 43(1) 36-56.

Kabel, C. (2016). Five lessons on successful philanthropic collaborations. [Blog post]. URL: http://effectivephilanthropy .org/five-lessons-on-successful-philanthropic-collaborations/ [April 21, 2016].

Kania, J., \& Kramer, M. (2011). Collective impact. Stanford Social Innovation Review. Winter 2011, 36-41.

Kania, J., \& Kramer, M. (2013, Winter). Embracing emergence: How collective impact addresses complexity. Stanford Social Innovation Review, 1-7.

Kania, J., Kramer, M., \& Russell, P. (2014, Summer). [With responses]. Strategic philanthropy for a complex world. Stanford Social Innovation Review, 26-39.

Kaufmann, J. (2011). Funders in collaboration: A review of the Corston Independent Funders' Coalition (CIFC). London, UK: Cass Business School of City University London.

Knight, B., \& Hartnell, C. (2011). Reframing the collaboration debate. Alliance Magazine,16(1), 28-33. 


\section{Glass \& Pole (2017)}

Kramer, L. (2014). Collaboration and "diffuse reciprocity." Stanford Social Innovation Review. URL: https://ssir.org larticles/entry/collaboration_and_diffuse_reciprocity [April 25, 2014].

Krapels, J., Disley, E., Corbett, J., Scraggs, E., \& Baruch, B. (2016). Evaluation of EPIM III 2012-2015. Cambridge, UK: RAND Europe.

Kubisch, A.C., Auspos, P., Brown, P., \& Dewar, T. (2011). Voices from the field III: Lessons and challenges from two decades of community-change efforts. The Foundation Review, 3(1\&2), 138-149.

Langlois, M. (2011). Building for uncharted seas: A funders collaborative. A case study and reflection tool of the Waterloo Region Resiliency Initiative. Waterloo, ON: Skipping Stones Consulting.

Leat, D. (2009). More than money: The potential of cross-sector relationships. London, UK: Big Lottery Fund and Association of Charitable Foundations Intelligent Funding Forum.

Lefèvre, S. (2015). Pour une approche sociopolitique de la philanthropie financière : plaidoyer pour un programme de recherche. Politique et sociétés, 34(2), 61-85.

Lewis, S.G., Friedmann, J., \& Schoneboom, J. (2010). Accomplishments of the Partnership for Higher Education in Africa, 2011-2010. Report on a decade of collaborative foundation investment. New York, NY: Carnegie Corporation \& Partnership for Higher Education in Africa.

Longtin, D. (2015a). Étude de cas sur le Groupe de travail des bailleurs de fonds pour le développement des jeunes enfants. Working paper\#6. Montréal, QC: PhiLab.

Longtin, D. (2015b). Portrait des réseaux de financement des membres du Canadian Environmental Grantmakers' Network. Working paper\#7. Montréal, QC: PhiLab.

MacKinnon, A. (2006). Working together to achieve greater impact: The Donors' Education Collaborative of New York City. Case Study No 3: Principles for Effective Education Grantmaking. Portland, OR: Grantmakers for Education.

Marek, L.I., Brock, D.P., \& Savla, J. (2015). Evaluating collaboration for effectiveness: Conceptualization and measurement. American Journal of Evaluation, 36(1), 67-85.

Marra, L. (2015). Three ways to maximize impact through collaboration. GMNsight, 6. URL: http://www.gmnsight.org /three-ways-to-maximize-impact-through-collaboration/ [April 2, 2016].

McCray, J. (2014). Is grantmaking getting smarter? A national field study of philanthropic practice. Washington, DC: Grantmakers for Effective Organizations.

McDougall, C.L. (2016). Northern Manitoba Food, Culture and Community Fund: An exploration of an innovative collaborative model. Working paper\#10. Montréal, QC: PhiLab.

Morris, T. (2014). The future of freshwater funding in Canada: Mobilizing collective resources for healthy watersheds. Toronto, ON: Canadian Environmental Grantmakers Network.

Morris, T. (2015). Collective impact: Nice buzz words or a transformative shift in how funders do business? CEGN Water Funders gathering backgrounder. Toronto, ON: Canadian Environmental Grantmakers Network.

Morris, T. (2017, March 13). Email communication with Juniper Glass.

Mulgan, G. (2016). Collaboration and collective impact: How can funders, NGOs, governments and citizens achieve more together? URL: http://www.nesta.org.uk/blog/collaboration-and-collective-impact [April 28, 2016].

Paarlberg, L.E, \& Meinhold, S.S. (2012). Using institutional theory to explore local variations in United Way's Community Impact model. Nonprofit and Voluntary Sector Quarterly, 41(5), 826-849.

Parker, S. (2010). Lessons from a ten-year funder collaborative: A case study of the Partnership for Higher Education in Africa. St. Johnsbury, VT: Clear Thinking Communications.

Patton, M.Q., Foote, N., \& Radner, J. (2015). A foundation's theory of philanthropy: What it is, what it provides, how to do it. The Foundation Review, 7(4), 7-20.

Patton, M.Q., \& Patrizi, P.A. (2010). Strategy as the focus for evaluation. New Directions for Evaluation, 128, 5-28.

Patrizi, P., \& Thompson, E.H. (2011). Beyond the veneer of strategic philanthropy. The Foundation Review, 2(3), 52-60. 


\section{Glass \& Pole (2017)}

Patrizi, P., Thompson, E.H., Coffman, J., Beer, T., (2013). Eyes wide open: Learning as strategy under conditions of complexity and uncertainty. The Foundation Review, 5(3), 50-65.

Pearson, H. (2010). Funder collaboratives: Trend or tool. The Philanthropist, 23(2), 120-125.

Pearson, H. (2014). Collective impact: Venturing on an unfamiliar road. The Philanthropist, 26(1), 49-53.

Pfitzer, M., \& Stamp, M. (2010). Multiplying impact through philanthropic collaboration. A report for the European Foundation Centre. Brussels: European Foundation Centre and FSG.

PhiLab. (n.d.). SSHRC partnership development project. Montréal, QC: PhiLab: The Montreal Research Laboratory on Canadian Philanthropy. URL: http://philab.uqam.ca/en/recherches/projet-crsh [March 5, 2017].

Philanthropic Foundations Canada. (2012). Funder collaboration: Making it work. 2012 PFC Symposium highlights. URL: www.pfc.ca [accessed February 25, 2015].

Philanthropic Foundations Canada. (2017). A Portrait of Canadian Foundation Philanthropy: Canada National Report for the Global Philanthropy Project at Harvard Kennedy School. Montréal, QC: Philanthropic Foundations Canada.

Pole, N., \& Community Foundations of Canada. (2015). Vital Signs: An exploratory case study of community foundations' local collaborations in a national program context. Working Paper \#8. Montréal, QC: PhiLab.

Pole, N. (2016). Collaboration among grantmaking foundations: A review of the literature. Working paper \#14. Montreal, QC: PhiLab.

Prager, J. (2011). Promise or pitfall? How foundations collaborate and develop partnerships. York, UK: Joseph Rowntree Charitable Trust.

Proscio, T. (2010). Common effort, uncommon wealth: Lessons from living cities on the challenges and opportunities of collaboration in philanthropy. Commissioned report for Living Cities. URL: https://www.livingcities.org/about/history [May 31, 2016].

Putnam-Walkerly, K., \& Russell, E. (2014). Many voices, one goal: How an informal foundation collaborative helped make California history. Cleveland, OH: Putnam Consulting Group.

Reich, R. (2013). What are foundations for? Boston Review, March/April. URL: http://www.bostonreview.net/forum /foundations-philanthropy-democracy [June 2, 2014].

Richardson, R. (2012). Funder collaboratives: Where the work touches the ground. Toronto, ON: Canadian Environmental Grantmakers Network.

Seldon, W., Tierney, T.J., \& Fernando, G. (2013, Spring). High stakes donor collaborations. Stanford Social Innovation Review, 45-51.

Silkes, S. (2016). Sustainable food systems: A landscape assessment for Canadian philanthropy. J.W. McConnell Family Foundation, Tides Canada, and Community Foundations of Canada.

The Philanthropic Initiative (2010). Donor collaboration: Power in numbers. Boston, MA: The Philanthropic Initiative.

Tomalty, R. (2013). Sustainable cities: The role for philanthropy in promoting urban sustainability. Toronto, ON: Canadian Environmental Grantmakers Network.

Turner, S., Merchant, K., Kania, J., \& Martin, E. (2012). Understanding the value of backbone organizations in collective impact. Stanford Social Innovation Review, July 2012, 17-20.

Wei-Skillern, J., Silver, N., \& Heitz, E. (2013). Cracking the network code: Four principles for grantmakers. Washington, DC: Grantmakers for Effective Organizations.

Wiley, P., Bierly, K., Reeve, T., \& Smith, K. (2013). When local solutions aren't enough: A strategic funding partnership to restore a large river system. The Foundation Review, 5(1), 89-104.

Woodland, R.H., \& Hutton, M.S. (2012). Evaluating organizational collaborations: Suggested entry points and strategies. American Journal of Evaluation, 33(3), 366-383. 


\section{Glass \& Pole (2017)}

\section{ABOUT THE AUTHORS / LES AUTEURS}

Juniper Glass, MPNL, is a nonprofit and philanthropic strategy consultant focused on social change philanthropy in Canada and Principal of Lumiere Consulting. She is a researcher at PhiLab, the Montreal Research Laboratory on Canadian Philanthropy, and a frequent contributor to The Philanthropist. Email: juniperglass@gmail.com .

Nancy Pole, MPNL, is an independent researcher and evaluation consultant we'll be Nancy Pole, MPNL, is an independent researcher, facilitator and and evaluation consultant who has worked with nonprofit and foundation collaboratives. She has completed several research mandates with PhiLab, the Montréal Research Laboratory on Canadian Philanthropy. Email: nancypole@co-spire.ca . 